\title{
Role of Lipid Peroxidation Products, Plasma Total Antioxidant Status, and Cu-, Zn-Superoxide Dismutase Activity as Biomarkers of Oxidative Stress in Elderly Prediabetics
}

\author{
Sylwia Dzięgielewska-Gęsiak, ${ }^{1}$ Ewa Wysocka, ${ }^{2}$ Sławomir Michalak, ${ }^{3,4}$ \\ Ewa Nowakowska-Zajdel, ${ }^{1}$ Teresa Kokot, ${ }^{1}$ and Małgorzata Muc-Wierzgoń ${ }^{1}$ \\ ${ }^{1}$ Teaching Department and Hospital Ward of Internal Diseases, Medical University of Silesia, Żeromskiego 7 Street, \\ 41-902 Bytom, Poland \\ ${ }^{2}$ Department of Clinical Biochemistry and Laboratory Medicine, Poznań University of Medical Sciences, \\ Grunwaldzka 6 Street, 61-702 Poznań, Poland \\ ${ }^{3}$ Department of Neurochemistry and Neuropathology, Poznan University of Medical Sciences, Przybyszewskiego 49 Street, \\ 60-355 Poznań, Poland \\ ${ }^{4}$ Neuroimmunology Unit, Polish Academy of Sciences, Przybyszewskiego 49 Street, 60-355 Poznań, Poland \\ Correspondence should be addressed to Sylwia Dzięgielewska-Gęsiak; syladzie@hotmail.com
}

Received 11 February 2014; Revised 17 April 2014; Accepted 21 April 2014; Published 5 May 2014

Academic Editor: Kota V. Ramana

Copyright (C) 2014 Sylwia Dzięgielewska-Gęsiak et al. This is an open access article distributed under the Creative Commons Attribution License, which permits unrestricted use, distribution, and reproduction in any medium, provided the original work is properly cited.

\begin{abstract}
The relationship between hyperglycemia and oxidative stress in diabetes is well known, but the influence of metabolic disturbances recognized as prediabetes, in elderly patients especially, awaits for an explanation. Methods. 52 elderly persons (65 years old and older) with no acute or severe chronic disorders were assessed: waist circumference (WC), body mass index (BMI), percentage of body fat (FAT), and arterial blood pressure. During an oral glucose tolerance test (OGTT) fasting $\left(0^{\prime}\right)$ and 120 -minute $\left(120^{\prime}\right)$ glycemia and insulinemia were determined, and type 2 diabetics $(n=6)$ were excluded. Subjects were tested for glycated hemoglobin HbAlc, plasma lipids, total antioxidant status (TAS), thiobarbituric acid-reacting substances (TBARS), and activity of erythrocyte superoxide dismutase (SOD-1). According to OGTT results, patients were classified as normoglycemics, (NGT, $n=18)$ and prediabetics, (PRE, $n=28$ ). Results. Both groups did not differ with their lipids, FAT, and TBARS. PRE group had higher WC $(P<0.002)$ and BMI $(P<0.002)$. Lower SOD-1 activity $(P<0.04)$ and TAS status $(P<0.04)$ were found in PRE versus NGT group. Significance. In elderly prediabetics, SOD-1 and TAS seem to reflect the first symptoms of oxidative stress, while TBARS are later biomarkers of oxidative stress.
\end{abstract}

\section{Introduction}

In the XXI century an elderly population (65 years old and older) will grow $[1,2]$. Studies on obesity, hypertension, dyslipidemia, and hyperglycemia in elderly population are currently widely discussed [3, 4]. Patients with type 2 diabetes mellitus suffer from late diabetic complications-atherosclerosis, hypertension, and dyslipidemia [5-7]. Chronic hyperglycemia leads to oxidative stress, dyslipoproteinemia, glycation of proteins, and endothelial dysfunction [8-10].
Over $40 \%$ of those affected by carbohydrate metabolism disturbances are 65 or older [11]. Among elderly subjects the late diabetic complications are more common. Many studies have been carried out to evaluate markers of free radicalinduced lipid peroxidation and antioxidant status in diabetic patients [12]. Thus, we know how diabetic hyperglycemia influences oxidant-antioxidant stress parameters [13], but still it is not clear in which way prediabetic hyperglycemia may influence metabolic balance in elderly patients. The oxidative stress may accompany and explain metabolic complications in hyperglycemic persons [14]. 
Hence, the present study has been undertaken, to evaluate the hypothesis that oxidative stress in elderly patients with increased risk for diabetes (prediabetes, impaired fasting glucose, IFG, and impaired glucose tolerance, IGT) is responsible, at least partially, for the clinical and metabolic complications. There is some evidence of early symptoms of cell damage caused by acute short-time elevated glucose concentration in medium, since changes of the $\mathrm{NAD}^{+} / \mathrm{NADH}$ ratio, mitochondrial membrane potential, and reactive oxygen species production were observed in human hepatic carcinoma model exposed to hyperglycemia-like in vitro situation [15].

An incomplete reduction of oxygen to water during electron transport chain in mitochondria is a possible source of oxygen-free radicals, that is, superoxide radical ${ }^{\circ} \mathrm{O}_{2}{ }^{-}$, in the elementary model of oxygen-free radical production. The following oxidative modification of biomolecules is discussed in many pathologies. The human body presents natural defense against free radicals: antioxidants preventing the formation of free radicals (i.e., metal-binding proteins), antioxidants scavenging free radicals and derivates: enzymatic (i.e., superoxide dismutase, catalases, glutathione peroxidase, and paraoxonase) and nonenzymatic (including vitamins, uric acid, bilirubin, and proteins) systems, and repair enzymes (targeting DNA especially). Cooper and zinc-containing superoxide dismutase, Cu-, Zn-SOD (SOD1), cytoplasmic enzyme, metabolizes superoxide radicals to molecular oxygen and hydrogen peroxide providing defence against oxygen toxicity [16].

The low-weight molecules are involved in the total plasma antioxidant status in the following proportions: $35-65 \%$ for uric acid, $10-50 \%$ for plasma proteins, $14 \%$ for vitamin C, and $7 \%$ for vitamin E [17], while other investigators assessed the detailed contribution of thiol groups (52.9\%), uric acid (33.1\%), vitamin C (4.7\%), bilirubin (2.4\%), vitamin E $1.7 \%$, and others (5.2\%) [18]. Researchers agree that due to the participation of many factors in the creation of plasma antioxidant defense and their possible variability, in pathological conditions of a significant share of oxidative stress, the total measurement could be more valuable [18]. Thus, intracellular antioxidant enzyme, the erythrocyte $\mathrm{Cu}$-, $\mathrm{Zn}$-superoxide dismutase (SOD-1), and the plasma total antioxidant status (TAS) as extracellular were chosen to describe the antioxidant potential. Thiobarbituric acid-reacting substances (TBARS) were to reflect plasma lipid peroxidation products.

\section{Material and Methods}

The study was performed under the permission from local ethics group in accordance with the Declaration of Helsinki of 1975 for Human Research and the study protocol was approved by the Bioethics Committee of Poznan University of Medical Sciences in Poznan, Poland (statements numbers $142 / 11$ and 595/11). The subjects participating in the study gave informed consent to the study procedure.

2.1. Subjects. This study enrolled 313 elderly Caucasians (65 years old and older) with no complains, from Poznan metropolitan area (west of Poland). Nonsmoking elderly persons, using no medication, no special diet, no supplements, and no alcohol, without acute or chronic disease, were studied. The exclusion criteria were the positive history of stroke, coronary artery disease (accompanied by current steadystate electrocardiography), diabetes, neoplastic disease, and inflammatory disease. Additional biochemical exclusion criteria were albuminuria reflected by albumin/creatinine ratio $>30 \mathrm{mg}$ of albumin $/ \mathrm{g}$ of creatinine in fresh morning urine sample and decreased eGFR (less than $60 \mathrm{~mL} / \mathrm{min}$ ) based on MDRD formula eGFR $\left(\mathrm{mL} / \mathrm{min} / 1.73 \mathrm{~m}^{2}\right)=\{186$ $\times[\text { creatinine }]^{-1.154} \times[\text { age }]^{-0,203} \times 0.742$ [for women] $\times$ 1.210 [for Afro-American]\}. Complete physical examination, including the measurement of waist circumference (WC), systolic (SBP) and diastolic (DBP) arterial blood pressure, percentage of body fat (FAT) measured by bioimpedance method using BodyStat equipment, and the calculation of body mass index $\left(\mathrm{BMI}=\mathrm{kg} / \mathrm{m}^{2}\right)$, was performed.

Finally 52 individuals were qualified for the $75 \mathrm{~g}$ oral glucose tolerance test (OGTT) due to WHO recommendations [19]. Results of OGTT allowed classifying subjects for normal glucose tolerance (NGT) $(n=18$, mean age 69.0 years $)$ and prediabetic (PRE) $(n=28$, mean age 71.0 years $)$ categories, while newly diagnosed type 2 diabetes mellitus (T2DM, $n=$ 6) patients were excluded from the study. The interpretation of oral glucose tolerance test is presented in Table 1 [20].

2.2. Blood Sampling and Biochemical Analysis. Blood was collected from the ulnar vein twice: fasting at $0 \mathrm{~min}\left(0^{\prime}\right)$ and at $120 \mathrm{~min}\left(120^{\prime}\right)$ of the $75 \mathrm{~g}$ OGTT. Fasting blood sample was used to measure the level of glycated hemoglobin $\left(\mathrm{HbA}_{1 \mathrm{c}}\right)$ as well as glucose, insulin, and lipid concentrations in plasma samples without symptoms of hemolysis. Oxidantantioxidant balance was measured in fasting blood samples. Blood collected at $120 \mathrm{~min}$ of OGTT was used for plasma glucose and insulin determinations.

2.2.1. Glucose, Lipid, Insulin, and $H b A_{1 c}$ Assays. Oral glucose tolerance test was performed according to WHO recommendations between 7.00 and $9.00 \mathrm{am}$. Glucose concentrations were determined at 0 minutes and 120 minutes of OGTT, following a standard dose of $75 \mathrm{~g}$ glucose load. Glucose and lipid parameters, including total cholesterol (T-C), high density lipoprotein cholesterol (HDL-C), and triacylglycerols (TAG) concentrations, were evaluated by enzymatic methods using bioMerieux reagent kit (Marcy-l'Etoile, France) and the UV-160A Shimadzu spectrophotometer (Shimadzu Co., Kyoto, Japan). Low density lipoprotein cholesterol (LDLC) was calculated using the Friedewald formula for lipid parameters expressed in $\mathrm{mmol} \cdot \mathrm{L}^{-1}$ : $[\mathrm{LDL}-\mathrm{C}]=[\mathrm{T}-\mathrm{C}]-$ [HDL-C] $-[0.45 \cdot \mathrm{TAG}]$, if TAG $<4.56 \mathrm{mmol} \cdot \mathrm{L}^{-1}$.

Insulin concentration was measured by an ELISA method (BioSOurce, Nivelles, Belgium) with sensitivity of $0.15 \mathrm{mU} \cdot \mathrm{L}^{-1}$, using microplate reader Sunrise (Tecan Group, Männedorf, Switzerland). The intra- and interassay coefficients of variation (CV) were $3.8 \%$ and $4.5 \%$, respectively.

Glycated hemoglobin $\left(\mathrm{HbA}_{1 \mathrm{c}}\right)$ level was determined by ion exchange high performance liquid chromatography using 
TABLE 1: The interpretation of oral glucose tolerance test (OGTT) adapted from [20].

\begin{tabular}{lcr}
\hline Categories of glycemia during OGTT & \multicolumn{2}{c}{ Plasma glucose concentration } \\
\hline Normal glucose tolerance (NGT) & Fasting (at $0 \mathrm{~min}$ ) & $<7.8 \mathrm{mmol} \cdot \mathrm{L}^{-1}$ \\
& $<5.6 \mathrm{mmol} \cdot \mathrm{L}^{-1}$ & $<140 \mathrm{mg} \cdot \mathrm{L}^{-1}$ \\
High risk of diabetes (prediabetes, PRE) & $<100 \mathrm{mg} \cdot \mathrm{L}^{-1}$ & \\
Impaired fasting glycemia (IFG) & & $<.6-6.9 \mathrm{mmol} \cdot \mathrm{L}^{-1}$ \\
& $100-125 \mathrm{mg} \cdot \mathrm{L}^{-1}$ & $<140 \mathrm{mg} \cdot \mathrm{L}^{-1}$ \\
Impaired glucose tolerance (IGT) & $<7.0 \mathrm{mmol} \cdot \mathrm{L}^{-1}$ & $7.8-11.0 \mathrm{mmol} \cdot \mathrm{L}^{-1}$ \\
& $<126 \mathrm{mg} \cdot \mathrm{L}^{-1}$ & $140-199 \mathrm{mg} \cdot \mathrm{L}^{-1}$ \\
Diabetes mellitus (DM) & $<7.0 \mathrm{mmol} \cdot \mathrm{L}^{-1}$ & $<11.1 \mathrm{mmol} \cdot \mathrm{L}^{-1}$ \\
\end{tabular}

D-10 Instrumentation (BioRad, Heidelberg, Germany) due to the national glycohemoglobin standardization program (USA), with the sensitivity $0.05 \%$ of $\mathrm{HbA}_{1 \mathrm{c}}$, and intra- and interassay $\mathrm{CV}$ for $\mathrm{HbA}_{1 \mathrm{c}}$ measurement were $5.0 \%$ and $6.8 \%$, respectively.

The Reference Sera. RANDOX Assayed Human Multi-Sera Level 1 (as normal) and RANDOX Assayed Human MultiSera Level 2 (as pathological) (Randox, Crumlin, United Kingdom) were used for monitoring the accuracy of the determinations.

2.2.2. Oxidative Stress Markers. Concentration of plasma total antioxidant status (TAS) and activity of erythrocyte cytoplasmatic superoxide dismutase $\mathrm{Cu}-, \mathrm{Zn}-\mathrm{SOD}$ (EC: 1.15.1.1) (SOD-1) were measured spectrophotometrically by a colorimetric assay based on the decrease of the optical density of the blank produced by each sample in analogy to its antioxidant property using Randox reagent kits (Randox Laboratories Ltd., Crumlin, Co. Antrim, United Kingdom) and Stat Fax 1904 Plus spectrometer (Awareness Technology, Inc., Palm City, Florida, USA).

Total Antioxidant Status (TAS). Total antioxidant status was carried out using $\mathrm{ABTS}^{+}\left(2,2^{\prime}\right.$-azino-bis(3ethylbenzothiazoline-6-sulphonic acid) radical formation kinetics. The presence of antioxidants in plasma suppressed the bluish-green staining of the ABTS cation, which was proportional to the antioxidant concentration level. Kinetics was measured at $600 \mathrm{~nm}$. The intra- and interassay CV for plasma TAS concentrations were $1.5 \%$ and $3.8 \%$, respectively.

Red Blood Cell Cu-, Zn-Superoxide Dismutase (SOD-1) EC: 1.15.1.1. The method employs xanthine and xanthine oxidase (XOD) to generate superoxide radicals, which react with 2-(4-iodophenyl)-3-(4-nitrophenol)-5-phenyltetrazolium chloride (INT) to form a red formazan dye. SOD-1 activity was measured by degree of inhibition of the reaction. Kinetics was measured at $505 \mathrm{~nm}$. The intra- and interassay CV for SOD-1 were $1.6 \%$ and $2.7 \%$, respectively.

Thiobarbituric Acid-Reacting Substances (TBARS). Concentration of plasma TBARS, reflecting plasma lipid peroxidation products, was determined by Okhawa method [21] using
Sigma reagents (Germany) and Specord M40 spectrometer (Germany). The intra- and interassay CV for TBARS were $1.8 \%$ and $3.7 \%$, respectively.

2.3. Statistical Analysis. Statistica 10.0 version for Windows was used for statistical analysis. The normality of value distribution was checked by Shapiro-Wilk test. Then, the results with a Gaussian distribution were analyzed with Student's $t$-test, and those with a non-Gaussian distribution were verified by a nonparametric Mann-Whitney $U$ test to assess the differences between studied NGT and PRE groups. The Spearman rank correlation test was used to evaluate the strength of association between two variables. Multiple regression analysis was performed to evaluate the relationship between independent variables and SOD-1 activity and TAS and TBARS concentrations. A $P<0.05$ was taken as indicative of significant differences. The results with a Gaussian distribution are expressed as mean and standard deviation (SD), and those with a non-Gaussian distribution are expressed as median and interquartile range.

The correlations between studied oxidative stress markers (TBARS, SOD-1, and TAS) and age, BMI, waist circumference, FAT, plasma lipids, HbA1c, G0', and G120' were tested with the use of multiple regression comparison. The analyzed models included the following:

(A) age, BMI, waist circumference (WC), and percentage of body fat (FAT) (Table 4);

(B) HbAlc, G0', and G120' (Table 5);

(C) SBP, DBP, age, BMI, FAT, and WC (Table 6);

(D) T-C, HDL-C, and TAG (LDL-C was not included as derivative of analyzed variables).

Analyzed subgroups of patients were as follows:

(i) females/males;

(ii) $\mathrm{AH}=0 / \mathrm{AH}=1$, as with no arterial hypertension $(\mathrm{AH}$ $=0)$ and with arterial hypertension $(\mathrm{AH}=1)$;

(iii) $\mathrm{G}^{\prime}=0 / \mathrm{GO}^{\prime}=1$, as with no fasting hyperglycemia $\left(\mathrm{G}^{\prime}=0\right)$ and with fasting hyperglycemia $\left(\mathrm{G}^{\prime}=1\right)$;

(iv) $\mathrm{PRE}=0 / \mathrm{PRE}=1$ as with no prediabetes $(\mathrm{PRE}=0)$ and with prediabetic states IFG or IGT $(\mathrm{PRE}=1)$. 
TABLE 2: The characteristics of the study groups. Data are presented as mean \pm SD for Gaussian distribution and median with interquartile range for the non-Gaussian distribution.

\begin{tabular}{|c|c|c|c|}
\hline & Total $n=46$ & NGT $n=18$ & $\operatorname{PRE} n=28$ \\
\hline Age (years) & $70.0(67.0-74.0)$ & $69.0(66.0-73.0)$ & $71.0(67.0-75.0)$ \\
\hline BMI $\left(\mathrm{kg} \cdot \mathrm{m}^{-2}\right)$ & $28.0(26.0-30.8)$ & $26.0(24.0-28.5)$ & $29.3(26.5-34.2)^{*}$ \\
\hline $\mathrm{WC}(\mathrm{cm})$ & $92.0(83.0-98.0)$ & $84.5(78.0-92.0)$ & $94.0(88.0-104.0)^{*}$ \\
\hline FAT (\%) & $37.2+/-15.2$ & $34.4+/-18.4$ & $38.6+/-12.8$ \\
\hline $\mathrm{SBP}(\mathrm{mmHg})$ & $140.0(130.0-145.0)$ & $132.5(125.0-145.0)$ & $140.0(135.0-145.0)$ \\
\hline DBP (mmHg) & $80.0(75.0-90.0)$ & $85.0(80.0-90.0)$ & $80.0(70.0-85.0)$ \\
\hline $\mathrm{G}^{\prime}\left(\mathrm{mmol} \cdot \mathrm{L}^{-1}\right)$ & $5.71(5.17-6.35)$ & $5.13(4.97-5.39)$ & $6.19(5.83-6.44)$ \\
\hline $\mathrm{G}^{2} 20^{\prime}\left(\mathrm{mmol} \cdot \mathrm{L}^{-1}\right)$ & $6.67(5.56-7.50)$ & $5.62(5.03-6.67)$ & $7.22(5.70-8.5)$ \\
\hline Ins $0^{\prime}\left(\mathrm{mU} \cdot \mathrm{L}^{-1}\right)$ & $30.83(16.39-34.66)$ & $29.25(16.39-31.93)$ & $32.85(16.54-37.44)$ \\
\hline Ins $120^{\prime}\left(\mathrm{mU} \cdot \mathrm{L}^{-1}\right)$ & $60.41(27.65-90.97)$ & $62.68(49.29-81.66)$ & $56.38(27.51-120.64)$ \\
\hline $\mathrm{HbA}_{1 \mathrm{c}}(\%)$ & $5.99(5.60-6.40)$ & $5.80(5.60-6.10)$ & $6.20(5.50-6.50)$ \\
\hline $\mathrm{T}-\mathrm{C}\left(\mathrm{mmol} \cdot \mathrm{L}^{-1}\right)$ & $5.13(4.64-5.70)$ & $5.71(4.79-5.78)$ & $5.05(4.61-5.67)$ \\
\hline TAG $\left(\mathrm{mmol} \cdot \mathrm{L}^{-1}\right)$ & $0.94+/-0.75$ & $1.24+/-0.59$ & $1.32+/-0.85$ \\
\hline $\mathrm{HDL}-\mathrm{C}\left(\mathrm{mmol} \cdot \mathrm{L}^{-1}\right)$ & $1.66(1.41-1.79)$ & $1.71(1.48-1.81)$ & $1.65(1.29-1.78)$ \\
\hline $\mathrm{LDL}-\mathrm{C}\left(\mathrm{mmol} \cdot \mathrm{L}^{-1}\right)$ & $2.90(2.49-3.46)$ & $3.11(2.58-3.54)$ & $2.79(2.45-3.24)$ \\
\hline SOD-1 (U.gHGB $\left.{ }^{-1}\right)$ & $1049.9(886.7-1257.9)$ & $1208.6(1002.4-1623.0)$ & $980.4(841.7-1137.2)^{*}$ \\
\hline TAS $\left(\mathrm{mmol} \cdot \mathrm{L}^{-1}\right)$ & $1.338(1.228-1.510)$ & $1.341(1.280-1.717)$ & $1.303(1.154-1.401)^{*}$ \\
\hline TBARS $\left(\mu \mathrm{mol} \cdot \mathrm{L}^{-1}\right)$ & $2.082(1.737-2.416)$ & $1,902(1.722-2.088)$ & $2.189(1.770-2.952)$ \\
\hline
\end{tabular}

* Significant difference, as compared to NGT group.

NGT: normal glucose tolerance, PRE: prediabetes states, FAT: percentage of body fat, BMI: body mass index, WC: waist circumference, SBP: systolic blood pressure, DBP: diastolic blood pressure, $\mathrm{GO}^{\prime}$ : fasting glucose, $\mathrm{G}_{120^{\prime}}$ : glucose at $120 \mathrm{~min}$ of oral glucose tolerance test (OGTT), Ins $0^{\prime}$ : fasting insulin, Ins $120^{\prime}$ : insulin at $120 \mathrm{~min}$ of OGTT, $\mathrm{HbA}_{\mathrm{lc}}$ : glycated hemoglobin, T-C: total cholesterol, TAG: triacylglycerols, HDL-C: high density lipoprotein cholesterol, LDL-C: low density lipoprotein cholesterol, SOD-1: Cu-, Zn-superoxide dismutase, TAS: total antioxidant status, and TBARS: thiobarbituric acid-reacting substances.

\section{Results}

The data in Table 2 show oxidative-antioxidative status and the clinical and biochemical characteristics of the groups. In the study population, prediabetes was diagnosed according to American Diabetes Association Standards for Medical Care 2013 [20] using OGTT and reflected $63.0 \%$ of IFG and $37.0 \%$ of IGT. Normoglycemic and prediabetes groups did not differ in lipid profile and percentage of body fat, but PRE group had higher waist circumference $(P<0.002)$ and BMI $(P<0.002)$. Concerning the oxidative stress markers, decreased SOD-1 $(P=0.033)$ and TAS $(P=0.039)$ and increased TBARS (no significance, $P=0.062$ ) were observed in the elderly prediabetics.

Correlation analysis considering oxidative stress markers and other parameters, in both groups, was performed (Table 3). In normoglycemic elderly subjects highly positive correlation between TAS and SOD was observed, whereas such an association was not found in the prediabetic group. However, in prediabetic subjects, a positive correlation between TAS and WC and a negative correlation between TAS and HDL-C were found. In addition, in PRE group, TBARS correlated positively with fasting glucose and HbAlc and negatively with age and BMI, whereas we did not observe such a correlation in the normoglycemic elderly group.

\section{Discussion}

Oxidative stress and failure of protein repair are one of the most discussed abnormalities in the aging process-both at the cellular and tissue levels [22, 23].

In the present study we investigated only elderly persons with or without prediabetic states to find out that oxidative stress and its markers depend not only on aging but also on hyperglycemia and its complications. Antioxidant defense systems, both located in the intracellular and extracellular spaces, are actively involved against reactive oxygen species, which are continuously generated in the body due to normal metabolism and disease. Studies concerning patients with late diabetic complications [24] or without them [25] have revealed a decrease in antioxidant defenses and an increase in oxidative damage markers. The authors of the present study investigated antioxidant status at the very early stages of hyperglycemia and found lower SOD-1 activity and plasma TAS in prediabetic elderly persons in comparison with normoglycemic ones.

Nakhjavani and colleagues suggested that the chronicity of DM promotes lipid peroxidation and malondialdehyde production, independent of glycemic control and antioxidant activity [26]. In our study we did not find any differences in the TBARS (as investigated for lipid peroxidation products) between normoglycemic and prediabetic elderly people, 
TABLE 3: The correlations between oxidative stress markers and clinical and biochemical parameters in the studied subjects.

\begin{tabular}{|c|c|c|c|c|c|c|c|c|c|c|c|c|}
\hline \multirow{3}{*}{ Variables } & \multicolumn{6}{|c|}{ NGT } & \multicolumn{6}{|c|}{ PRE } \\
\hline & \multicolumn{2}{|c|}{ SOD-1 } & \multicolumn{2}{|c|}{ TAS } & \multicolumn{2}{|c|}{ TBARS } & \multicolumn{2}{|c|}{ SOD-1 } & \multicolumn{2}{|c|}{ TAS } & \multicolumn{2}{|c|}{ TBARS } \\
\hline & $R$ & $P$ & $R$ & $P$ & $R$ & $P$ & $R$ & $P$ & $R$ & $P$ & $R$ & $P$ \\
\hline Age & -0.379 & 0.120 & -0.258 & 0.301 & 0.341 & 0.166 & 0.245 & 0.218 & 0.024 & 0.907 & -0.659 & $<0.001$ \\
\hline BMI & 0.229 & 0.360 & -0.012 & 0.961 & 0.198 & 0.430 & 0.192 & 0.924 & 0.115 & 0.567 & -0.437 & 0.023 \\
\hline WC & -0.174 & 0.491 & -0.215 & 0.391 & 0.337 & 0.172 & 0.209 & 0.295 & 0.398 & 0.040 & -0.164 & 0.413 \\
\hline FAT & -0.034 & 0.893 & -0.106 & 0.675 & 0.242 & 0.332 & 0.200 & 0.585 & 0.042 & 0.835 & -0.366 & 0.061 \\
\hline SBP & -0.028 & 0.912 & -0.203 & 0.418 & 0.229 & 0.360 & -0.159 & 0.429 & 0.113 & 0.574 & 0.057 & 0.777 \\
\hline DBP & 0.017 & 0.946 & -0.105 & 0.677 & -0.044 & 0.863 & -0.068 & 0.738 & 0.185 & 0.357 & -0.204 & 0.307 \\
\hline $\mathrm{G}^{\prime}$ & 0.189 & 0.453 & 0.130 & 0.607 & 0.032 & 0.900 & -0.318 & 0.106 & -0.080 & 0.693 & 0.407 & 0.035 \\
\hline G120' & -0.057 & 0.823 & -0.118 & 0.639 & 0.358 & 0.144 & 0.062 & 0.759 & -0.029 & 0.886 & 0.314 & 0.110 \\
\hline Ins $0^{\prime}$ & -0.154 & 0.542 & -0.349 & 0.155 & 0.120 & 0.636 & -0.052 & 0.794 & 0.422 & 0.025 & -0.403 & 0.033 \\
\hline Ins $120^{\prime}$ & -0.135 & 0.593 & -0.244 & 0.328 & 0.253 & 0.311 & 0.214 & 0.273 & 0.104 & 0.597 & 0.177 & 0.368 \\
\hline $\mathrm{HbA}_{1 \mathrm{c}}$ & -0.140 & 0.579 & -0.003 & 0.990 & 0.351 & 0.153 & -0.056 & 0.779 & -0.093 & 0.645 & 0.503 & 0.007 \\
\hline T-C & 0.320 & 0.195 & 0.272 & 0.275 & -0.012 & 0.961 & 0.055 & 0.786 & -0.200 & 0.317 & 0.186 & 0.354 \\
\hline TAG & 0.020 & 0.936 & 0.041 & 0.872 & 0.118 & 0.642 & -0.255 & 0.199 & 0.040 & 0.843 & 0.082 & 0.684 \\
\hline HDL-C & 0.174 & 0.489 & 0.236 & 0.345 & -0.170 & 0.499 & -0.029 & 0.885 & -0.568 & 0.002 & -0.194 & 0.332 \\
\hline LDL-C & 0.376 & 0.123 & 0.234 & 0.349 & -0.141 & 0.576 & 0.173 & 0.387 & -0.025 & 0.902 & 0.222 & 0.266 \\
\hline SOD-1 & - & - & 0.864 & $<0.001$ & -0.416 & 0.086 & - & - & 0.225 & 0.258 & -0.052 & 0.795 \\
\hline TAS & 0.864 & $<0.001$ & - & - & -0.178 & 0.478 & 0.225 & 0.258 & - & - & -0.221 & 0.267 \\
\hline TBARS & -0.416 & 0.086 & -0.178 & 0.478 & - & - & -0.052 & 0.795 & -0.221 & 0.267 & - & - \\
\hline
\end{tabular}

NGT: normal glucose tolerance, PRE: prediabetes states, FAT: percentage of body fat, BMI: body mass index, WC: waist circumference, SBP: systolic blood pressure, DBP: diastolic blood pressure, $\mathrm{GO}^{\prime}$ : fasting glucose, $\mathrm{G}^{2} 20^{\prime}$ : glucose at $120 \mathrm{~min}$ of oral glucose tolerance test (OGTT), Ins $0^{\prime}$ : fasting insulin, Ins $120^{\prime}$ : insulin at 120 min of OGTT, $\mathrm{HbA}_{1 \mathrm{c}}$ : glycated hemoglobin, T-C: total cholesterol, TAG: triacylglycerols, HDL-C: high density lipoprotein cholesterol, LDL-C: low density lipoprotein cholesterol, SOD-1: Cu-, Zn-superoxide dismutase, TAS: total antioxidant status, and TBARS: thiobarbituric acid-reacting substances.

TABLE 4: The significant correlations in the multiple regression analysis between oxidative stress markers and clinical and biochemical parameters in the model A, including age, BMI, waist, and FAT.

\begin{tabular}{|c|c|c|c|c|c|}
\hline & $B$ & Beta & $P$ & $r$ & $R^{2}$ \\
\hline $\begin{array}{l}\text { TBARS and age } \\
\text { All subjects }\end{array}$ & 3.6400 & -0.02746 & 0.0462 & -0.3008 & 0.1175 \\
\hline $\begin{array}{l}\text { TBARS and waist } \\
\text { Males }\end{array}$ & 2.4462 & 0.02728 & 0.0215 & 0.3240 & 0.5515 \\
\hline $\begin{array}{l}\text { TBARS and age } \\
\mathrm{GO}^{\prime}=1\end{array}$ & 5.9268 & -0.03448 & 0.0402 & -0.4909 & 0.3053 \\
\hline $\begin{array}{l}\text { TBARS and age } \\
\text { Pre }=1\end{array}$ & 6.1224 & -0.03550 & 0.0347 & -0.5050 & 0.3379 \\
\hline $\begin{array}{l}\text { SOD- } 1 \text { and BMI } \\
\mathrm{G} 0^{\prime}=0\end{array}$ & 3235.9562 & 59.4009 & 0.0405 & 0.2569 & 0.4653 \\
\hline $\begin{array}{l}\text { SOD }-1 \text { and BMI } \\
\text { PRE }=0\end{array}$ & 2522.5913 & 66.3857 & 0.0340 & 0.4116 & 0.4653 \\
\hline $\begin{array}{l}\text { TAS and FAT } \\
\mathrm{G}^{\prime}=0\end{array}$ & 3.0917 & -0.008491 & 0.0433 & -0.4332 & 0.4150 \\
\hline
\end{tabular}

PRE $=0$ : no prediabetes states, $\mathrm{PRE}=1$ : prediabetes states, $\mathrm{G}^{\prime}=0$ : no hyperglycemia, $\mathrm{G} 0^{\prime}=1$ : fasting hyperglycemia, FAT: percentage of body fat, $\mathrm{BMI}$ : body mass index, SOD-1: Cu-, Zn-superoxide dismutase, TAS: total antioxidant status, and TBARS: thiobarbituric acid-reacting substances.

whereas SOD-1 and TAS were lower in prediabetic ones. Thus, we suggest that antioxidant capacity is the first marker which declines in prediabetic elderly people. Kumawat and colleagues concluded that there is enhanced oxidative stress and decreased antioxidant defense in geriatrics as compared to younger counterparts [27]. However, their elderly group had highly increased total cholesterol, triacylglycerols, LDLcholesterol, and decreased HDL-cholesterol. We investigated only elderly population with lipid profile within references but with or without hyperglycemia and thus we suggest that decreased antioxidant capacity is rather due to hyperglycemia than aging itself.

It is important to note that longer duration of hyperglycemia and chronic diabetes complications are associated with older age [28]. Our findings showed strong positive correlation between SOD-1 and TAS in elderly normoglycemic 
TABLE 5: The significant correlations in the multiple regression analysis between oxidative-antioxidative status and clinical and biochemical parameters in the model $\mathrm{B}$, including $\mathrm{HbA}_{\mathrm{lc}}, \mathrm{GO}^{\prime}$, and $\mathrm{G} 120^{\prime}$.

\begin{tabular}{|c|c|c|c|c|c|}
\hline & $B$ & Beta & $P$ & $r$ & $R^{2}$ \\
\hline $\begin{array}{l}\text { TBARS and } \mathrm{HbA}_{\mathrm{lc}} \\
\text { All subjects }\end{array}$ & -2.4365 & 0.4511 & 0.0225 & 0.5422 & 0.4118 \\
\hline $\begin{array}{l}\text { TBARS and } \mathrm{HbA}_{\mathrm{lc}} \\
\text { Females }\end{array}$ & -2.6736 & 0.5289 & 0.0479 & 0.6294 & 0.4893 \\
\hline $\begin{array}{l}\text { TBARS and } \mathrm{HbA}_{\mathrm{lc}} \\
\mathrm{AH}=1\end{array}$ & -2.4637 & 0.4848 & 0.0369 & 0.4812 & 0.3533 \\
\hline $\begin{array}{l}\text { TBARS and } \mathrm{GO}^{\prime} \\
\mathrm{AH}=1\end{array}$ & -2.4637 & 0.01756 & 0.0255 & 0.4844 & 0.3533 \\
\hline $\begin{array}{l}\text { TBARS and } \mathrm{G}^{\prime} \\
\text { All subjects }\end{array}$ & -2.4365 & 0.01504 & 0.0317 & 0.4959 & 0.4118 \\
\hline $\begin{array}{l}\text { SOD-1 and G0' } \\
\text { Females }\end{array}$ & 2473.4391 & -15.0145 & 0.0293 & -0.4508 & 0.2075 \\
\hline $\begin{array}{l}\text { TAS and G0' } \\
\text { Females }\end{array}$ & 1.8850 & -0.01307 & 0.0159 & -0.4636 & 0.2567 \\
\hline $\begin{array}{l}\text { TAS and } \mathrm{GO}^{\prime} \\
\mathrm{AH}=0\end{array}$ & 3.5926 & -0.04342 & 0.0184 & -0.7862 & 0.8063 \\
\hline
\end{tabular}

$\mathrm{AH}=0$ : no arterial hypertension, $\mathrm{AH}=1$ : with arterial hypertension, $\mathrm{GO}^{\prime}$ : fasting glycemia, $\mathrm{Hb}_{1 \mathrm{c}}$ : glycated hemoglobin, $\mathrm{SOD}-1$ : Cu-, $\mathrm{Zn}$-superoxide dismutase, TAS: total antioxidant status, and TBARS: thiobarbituric acid-reacting substances.

TABLE 6: The significant correlations in the multiple regression analysis between oxidative-antioxidative status and the clinical and biochemical parameters in the model C including SBP, DBP, age, BMI, FAT, and waist.

\begin{tabular}{|c|c|c|c|c|c|}
\hline & $B$ & Beta & $P$ & $r$ & $R^{2}$ \\
\hline $\begin{array}{l}\text { TBARS and SBP } \\
\text { All subjects }\end{array}$ & 3.7117 & 0.01727 & 0.0205 & 0.2325 & 0.3167 \\
\hline $\begin{array}{l}\text { TBARS and SBP } \\
\text { Females }\end{array}$ & 3.4882 & 0.01664 & 0.0470 & 0.2276 & 0.3941 \\
\hline $\begin{array}{l}\text { TBARS and SBP } \\
\mathrm{AH}=1\end{array}$ & 4.5396 & 0.01606 & 0.0479 & 0.2090 & 0.4041 \\
\hline $\begin{array}{l}\text { TBARS and DBP } \\
\text { All subjects }\end{array}$ & 3.7117 & -0.02932 & 0.0051 & -0.2777 & 0.3167 \\
\hline $\begin{array}{l}\text { TBARS and DBP } \\
\text { Females }\end{array}$ & 3.4882 & -0.03155 & 0.0221 & -0.3767 & 0.3941 \\
\hline $\begin{array}{l}\text { TBARS and DBP } \\
\mathrm{AH}=1\end{array}$ & 4.5396 & -0.02766 & 0.0108 & -0.4208 & 0.4041 \\
\hline $\begin{array}{l}\text { TBARS and age } \\
\mathrm{AH}=1\end{array}$ & 4.5396 & -0.03200 & 0.0485 & -0.3471 & 0.4041 \\
\hline $\begin{array}{l}\text { SOD and BMI } \\
\mathrm{G}^{\prime}=0\end{array}$ & 2678.6219 & 64.3659 & 0.0473 & 0.2569 & 0.4946 \\
\hline
\end{tabular}

$\mathrm{AH}=0$ : no arterial hypertension, $\mathrm{AH}=1$ : with arterial hypertension, $\mathrm{GO}^{\prime}=0$ : no fasting hyperglycemia, $\mathrm{G} 0^{\prime}=1$ : fasting hyperglycemia, $\mathrm{BMI}$ : body mass index, SBP: systolic blood pressure, DBP: diastolic blood pressure, SOD-1: Cu-, Zn-superoxide dismutase, TAS: total antioxidant status, and TBARS: thiobarbituric acid-reacting substances.

subjects, whereas in prediabetic ones there is deactivation between intra- and extracellular antioxidative state (Table 3).

The authors of the present work found an interesting negative correlation between TAS and HDL-C in prediabetic elderly people, independent of other metabolic factors (Table 7). The linear changes of plasma HDL-C concentration may accompany or even supplement $28 \%$ of plasma TAS variability. This suggests the complementarity of these two important antioxidant factors in elderly patients with high risk for T2DM. It also supports the current suggestion about HDL function in humans, what was pointed out not only in
hyper-LDL-C patients but in normal low density lipoprotein levels patients as well [29].

A very interesting work was published by Bandeira and colleagues, and they found correlation between lipid peroxidation and diabetes mellitus irrespective of the presence of hypertension [30]. In the present work the multiple regression analysis showed negative correlation between TAS and fasting glycemia in those without hypertension, what suggests that fasting glucose in $80 \%$ accompanies TAS in the preservation of development of hypertension and positive correlation between TBARS and fasting glycemia in 
TABLE 7: The significant correlations in the multiple regression analysis between studied oxidative-antioxidative status and clinical and biochemical parameters in the model D including TC, HDL-C, and TAG (LDL-C not included as a derivative of analyzed variables).

\begin{tabular}{lcccr}
\hline & $B$ & Beta & $P$ & $r$ \\
\hline $\begin{array}{l}\text { SOD and TC } \\
\text { All subjects }\end{array}$ & 811.6939 & 3.6717 & 0.0421 & 0.2094 \\
TAS and HDL & 1.8910 & -0.009533 & 0.0245 & -0.5293 \\
$\begin{array}{l}\text { G0 }{ }^{\prime}=1 \\
\text { TAS and HDL }\end{array}$ & 1.9046 & -0.009167 & 0.0309 & -0.5320 \\
PRE $=1$ & & & 0.2806 \\
\hline
\end{tabular}

$\mathrm{G0}^{\prime}=0$ : no fasting hyperglycemia, $\mathrm{G}^{\prime}=1$ : fasting hyperglycemia, $\mathrm{PRE}=0$ : no prediabetes, $\mathrm{PRE}=1$ : prediabetes, TC: total cholesterol, HDL-C: high density lipoprotein cholesterol, SOD-1: $\mathrm{Cu}-, \mathrm{Zn}$-superoxide dismutase, and TAS: total antioxidant status.

those with developed hypertension, which is the next point of developing chronic complications in elderly prediabetic patients. Thus, we suggest that disturbances in the oxidativeantioxidative status may serve as very early markers of chronic complications of hyperglycemia.

Limitation of the Study. Although there is much that remains to be done, our work generates important findings in the field of antioxidant capacity among elderly population. We confirm that there are some limitations of this study. The main limitation is small elderly group, but it is hard to find elderly subjects without complaints, with no acute and/or chronic diseases, using no medication or supplements. Future research would have been more convincing if the researchers would have more elderly subjects with the very early hyperglycemia state both impaired glucose tolerance and impaired fasting glycemia.

\section{Conclusions}

In elderly patients metabolic factors differ among prediabetic and normoglycemic patients leading to disturbances in oxidative-antioxidative state. Erythrocyte SOD-1 activity and plasma TAS are lower in elderly prediabetics in comparison with normoglycemic cases revealing deactivation of antioxidative capacity by hyperglycemia in elderly patients. In elderly prediabetic subjects, TBARS did not differ significantly in comparison with control group, indicating early oxidative stress. Thus, SOD-1 and TAS are suggested to be the very early biomarkers in the course of hyperglycemic complication among prediabetic elderly people. Identification of pathomechanisms involved in disturbances of carbohydrate metabolism in the course of early diabetes stages enables the explanation of chronic diabetic complications leading to optimization of the treatment in elderly hyperglycemic cases.

\section{Disclosure}

This study is a part of Poznan University of Medical Sciences Research Project no. 501-01-2228369-00260.

\section{Conflict of Interests}

All authors disclose no conflict of interests in relation to this work.

\section{Acknowledgments}

The authors would like to thank all the patients for the study performance. They also would like to thank Professor Lech Torliński M.D., Ph.D., for supervising the research.

\section{References}

[1] United Nations, World Population Ageing 2009, Sales no. E.10.XIII.5, Population Division, Department of Economic and Social Affairs, United Nations, New York, NY, USA, 2010.

[2] H. Arai, Y. Ouchi, M. Yokode et al., "Toward the realization of a better aged society: messages from gerontology and geriatrics," Geriatrics \& Gerontology International, vol. 12, no. 1, pp. 16-22, 2012.

[3] A. K. Welmer, S. Angleman, E. Rydwik, L. Fratiglioni, and C. Qiu, "Association of cardiovascular burden with mobility limitation among elderly people: a population-based study," PLoS ONE, vol. 8, no. 5, article e65815, 2013.

[4] F. J. Félix-Redondo, M. Grau, J. M. Baena-Díez et al., "Prevalence of obesity and associated cardiovascular risk: the DARIOS study," BMC Public Health, vol. 13, no. 1, article 542, 2013.

[5] International Diabetes Federation, IDF Diabetes Atlas, International Diabetes Federation, Brussels, Belgium, 5th edition, 2012.

[6] G. Roglic and N. Unwin, "Mortality attributable to diabetes: estimates for the year 2010," Diabetes Research and Clinical Practice, vol. 87, no. 1, pp. 15-19, 2010.

[7] M. J. Fowler, "Microvascular and macrovascular complications of diabetes," Clinical Diabetes, vol. 29, no. 3, pp. 116-122, 2011.

[8] Y. Su, X. M. Liu, Y. M. Sun et al., “The relationship between endothelial dysfunction and oxidative stress in diabetes and prediabetes," The International Journal of Clinical Practice, vol. 62 , no. 6, pp. 877-882, 2008.

[9] E. Nobécourt, S. Jacqueminet, B. Hansel et al., "Defective antioxidative activity of small dense HDL3 particles in type 2 diabetes: relationship to elevated oxidative stress and hyperglycaemia," Diabetologia, vol. 48, no. 3, pp. 529-538, 2005.

[10] D. Gradinaru, C. Borsa, C. Ionescu, and D. Margina, "Advanced oxidative and glycoxidative protein damage markers in the elderly with type 2 diabetes," Journal of Proteomics, vol. 92, pp. 313-322, 2013.

[11] N. de Rekeneire, R. Peila, J. Ding et al., "Diabetes, hyperglycemia, and inflammation in older individuals. The Health, Aging and Body Composition study," Diabetes Care, vol. 29, no. 8, pp. 1902-1908, 2006. 
[12] A. C. Maritim, R. A. Sanders, and J. B. Watkins III, "Diabetes, oxidative stress, and antioxidants: a review," Journal of Biochemical and Molecular Toxicology, vol. 17, no. 1, pp. 24-38, 2003.

[13] U. Karunakaran and K. G. Park, "A systematic review of oxidative stress and safety of antioxidants in diabetes: focus on islets and their defense," Diabetes \& Metabolism Journal, vol. 37, no. 2, pp. 106-112, 2013.

[14] M. Kaplan, M. Aviram, and T. Hayek, "Oxidative stress and macrophage foam cell formation during diabetes mellitusinduced atherogenesis: role of insulin therapy," Pharmacology \& Therapeutics, vol. 136, no. 2, pp. 175-185, 2012.

[15] J. S. Teodoro, A. P. Gomes, A. T. Varela, F. V. Duarte, A. P. Rolo, and C. M. Palmeira, "Uncovering the beginning of diabetes: the cellular redox status and oxidative stress as starting players in hyperglycemic damage," Molecular and Cellular Biochemistry, vol. 376, no. 1-2, pp. 103-110, 2013.

[16] M. Valko, D. Leibfritz, J. Moncol, M. T. D. Cronin, M. Mazur, and J. Telser, "Free radicals and antioxidants in normal physiological functions and human disease," The International Journal of Biochemistry \& Cell Biology, vol. 39, no. 1, pp. 44-84, 2007.

[17] W. Stahl and H. Sies, "Antioxidant defense: vitamins E and C and carotenoids," Diabetes, vol. 46, supplement 2, pp. S14-S18, 1997.

[18] O. Erel, "A novel automated direct measurement method for total antioxidant capacity using a new generation, more stable ABTS radical cation," Clinical Biochemistry, vol. 37, no. 4, pp. 277-285, 2004.

[19] World Health Organization, "Prevention of diabetes mellitus," Tech. Rep. 844, World Health Organization, Geneva, Switzerland, 1994.

[20] American Diabetes Association, "Standards of medical care in diabetes-2013," Diabetes Care, vol. 36, supplement 1, pp. S11S66, 2013.

[21] H. Ohkawa, N. Ohishi, and K. Yagi, "Assay for lipid peroxides in animal tissues by thiobarbituric acid reaction," Analytical Biochemistry, vol. 95, no. 2, pp. 351-358, 1979.

[22] V. A. Bohr, "Repair of oxidative DNA damage in nuclear and mitochondrial DNA, and some changes with aging in mammalian cells," Free Radical Biology and Medicine, vol. 32, no. 9, pp. 804-812, 2002.

[23] E. R. Stadtman, "Protein oxidation and aging," Free Radical Research, vol. 40, no. 12, pp. 1250-1258, 2006.

[24] D. Ziegler, C. G. H. Sohr, and J. Nourooz-Zadeh, "Oxidative stress and antioxidant defense in relation to the severity of diabetic polyneuropathy and cardiovascular autonomic neuropathy," Diabetes Care, vol. 27, no. 9, pp. 2178-2183, 2004.

[25] J. Kasznicki, M. Kosmalski, A. Sliwinska et al., "Evaluation of oxidative stress markers in pathogenesis of diabetic neuropathy," Molecular Biology Reports, vol. 39, no. 9, pp. 8669-8678, 2012.

[26] M. Nakhjavani, A. Esteghamati, S. Nowroozi, F. Asgarani, A. Rashidi, and O. Khalilzadeh, "Type 2 diabetes mellitus duration: an independent predictor of serum malondialdehyde levels," Singapore Medical Journal, vol. 51, no. 7, pp. 582-585, 2010.

[27] M. Kumawat, T. K. Sarama, I. Singh et al., "Decrease in antioxidant status of plasma and erytrocytes from geriatric population," Disease Markers, vol. 33, no. 6, pp. 303-308, 2012.

[28] I. Suciu, V. Negrean, and D. Sâmpelean, "The oxidative stress in the development of diabetes chronic complications in the elderly," Romanian Journal of Internal Medicine, vol. 42, no. 2, pp. 395-406, 2004.
[29] S. M. Seo, E.-H. Choo, Y.-S. Koh et al., "High-density lipoprotein cholesterol as a predictor of clinical outcomes in patients achieving low-density lipoprotein cholesterol targets with statins after percutaneous coronary intervention," Heart, vol. 97, no. 23, pp. 1943-1950, 2011.

[30] S. D. M. Bandeira, G. D. S. Guedes, L. J. S. da Fonseca et al., "Characterization of blood oxidative stress in type 2 diabetes mellitus patients: increase in lipid peroxidation and SOD activity," Oxidative Medicine and Cellular Longevity, vol. 2012, Article ID 819310, 13 pages, 2012. 


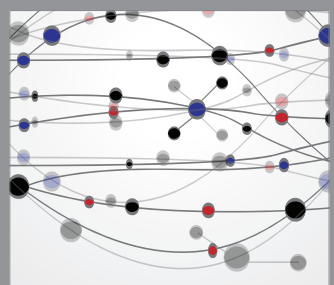

The Scientific World Journal
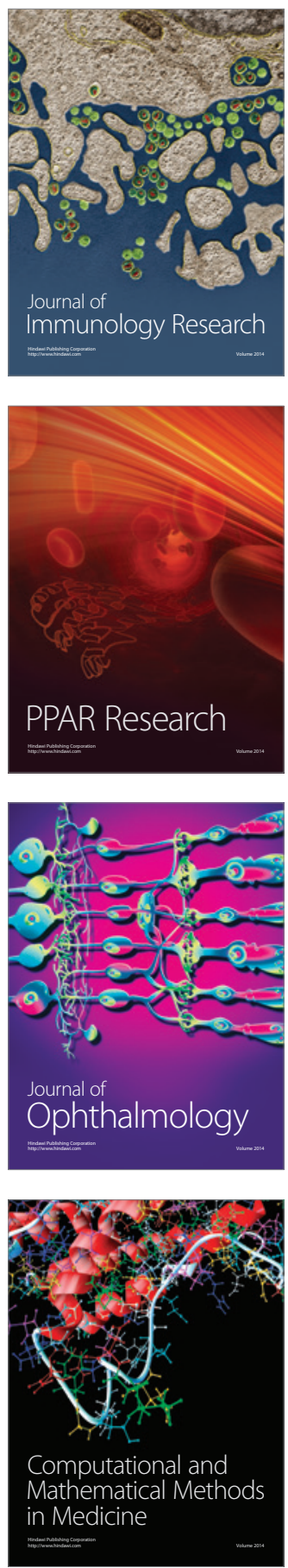

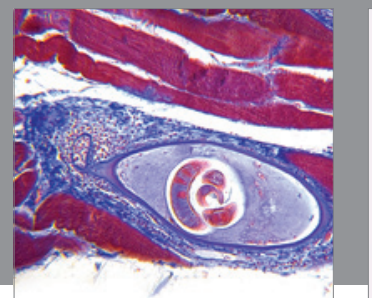

Gastroenterology

Research and Practice
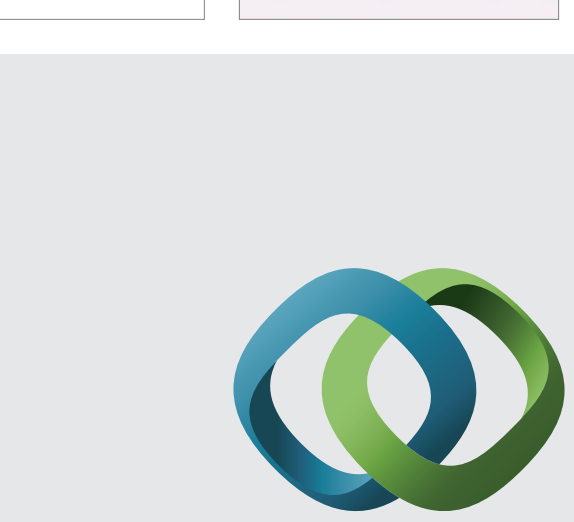

\section{Hindawi}

Submit your manuscripts at

http://www.hindawi.com
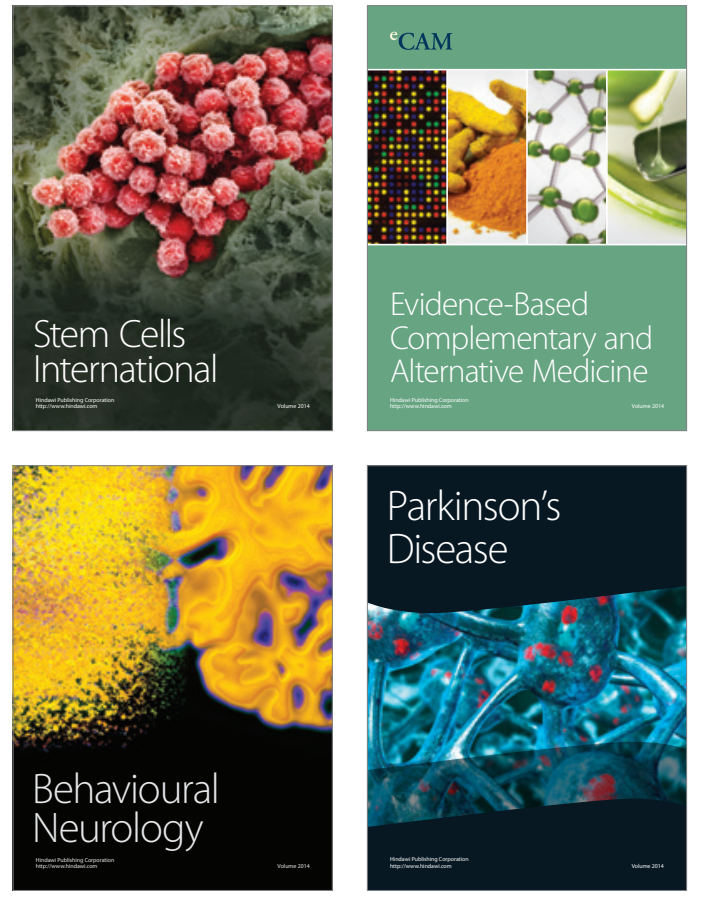
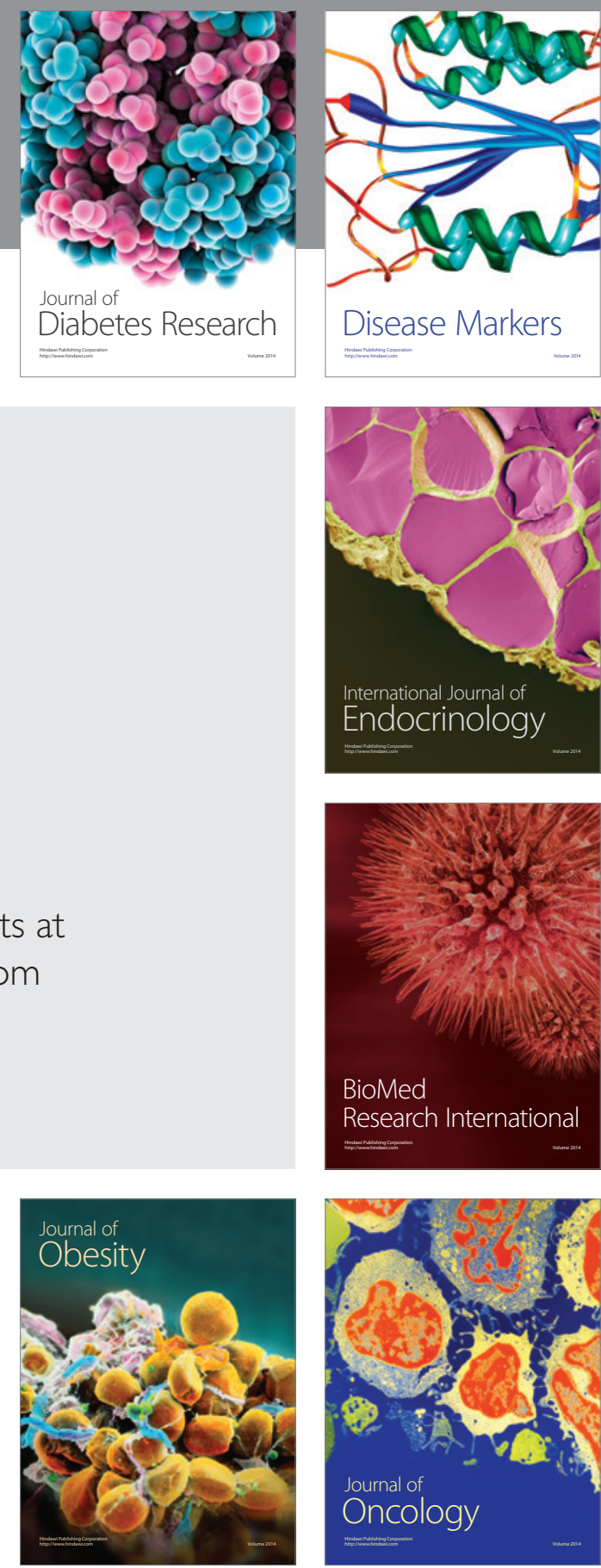

Disease Markers
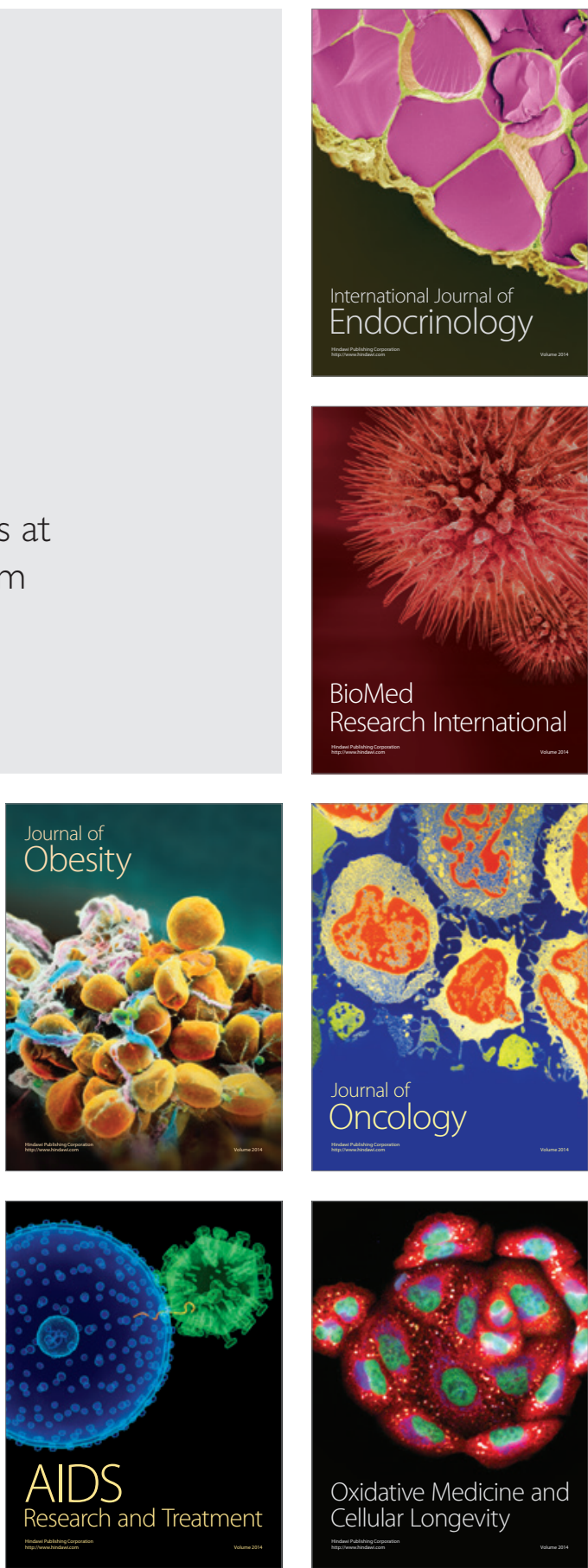